\title{
Properties of Hydrochar as Function of Feedstock, Reaction Conditions and Post-Treatment
}

\author{
Andrea Kruse ${ }^{1, *}$ and Thomas A. Zevaco ${ }^{2}$ \\ 1 Institute of Agricultural Engineering, Chair of Conversion Technologies of Biobased Resources, \\ University of Hohenheim, Garbenstrasse 9, 70599 Stuttgart, Germany \\ 2 Karlsruhe Institute of Technology, Institute for Catalysis Research and Technology, \\ Hermann-von-Helmholtz-Platz 1, 76344 Eggenstein-Leopoldshafen, Germany; thomas.zevaco@kit.edu \\ * Correspondence: Andrea_Kruse@uni-hohenheim.de; Tel.: +49-711-450-24700
}

Received: 13 February 2018; Accepted: 14 March 2018; Published: 16 March 2018

\begin{abstract}
Hydrothermal carbonization (HTC) is a promising technology to convert wet biomass into carbon-rich materials. Until now, the chemical processes occurring and their influence on the product properties are not well understood. Therefore, a target-oriented production of materials with defined properties is difficult, if not impossible. Here, model compounds such as cellulose and lignin, as well as different definite biomasses such as straw and beech wood are converted by hydrothermal carbonization. Following this, thermogravimetic (TGA) and FTIR measurements are used to get information about chemical structure and thermal properties of the related hydrochars. Some of the isolated materials are thermally post-treated $\left(490^{\circ} \mathrm{C}\right.$ and $\left.700{ }^{\circ} \mathrm{C}\right)$ and analyzed. The results show that at "mild" HTC conversion, the cellulose part in a lignocellulose matrix is not completely carbonized and there is still cellulose present. Thermal post-treatment makes the properties of product materials more similar and shows complete carbonization with increase aromatic cross-linking, proven by TGA and FTIR results.
\end{abstract}

Keywords: hydrothermal carbonization (HTC); hydrothermal; carbonization; cellulose; lignin; thermogravimetric analysis; differential thermogravimetry (DTG); Fourier transform infrared spectroscopy (FTIR)

\section{Introduction}

Hydrothermal carbonization (HTC) has found an increasing interest, mainly in view of the opportunities to produce advanced carbon materials [1-5]. On the other hand, knowledge is still missing concerning the processes that happen during hydrothermal carbonization. Two main reaction pathways are likely to occur: on the one hand hydrolysis of the starting material followed by water elimination and consecutive polymerization to "coke". Hydroxymethylfurfural (HMF) obtained from hexoses and furfural from pentoses are the most important intermediates forming the carbon-rich material. Usually, if only this reaction pathway A (Figure 1) occurs, micro spheres are formed (see scanning electron microscope (SEM) picture left in Figure 1). In Figure 1 this carbon-rich material is typically called "coke", because of its formation via polymerization like coke in high-temperature dry conversions. On the other hand, the second pathway B (Figure 1) is a solid-to-solid conversion similar to charring phenomena found in dry conversions (mainly at low-temperature) [6,7]. The product of HTC, however it is formed, is usually called hydrochar.

The temperatures used in HTC (around $200{ }^{\circ} \mathrm{C}$ ) are too low to convert lignin completely [8]. Typically, under these experimental conditions a particle stays solid and in the original shape. The composition changes slightly [8] and some holes are formed (Figure 1, right picture at the bottom). This means that lignin mainly reacts via a solid-to-solid conversion, shown as reaction pathway B in Figure 1 (see also [9]). 

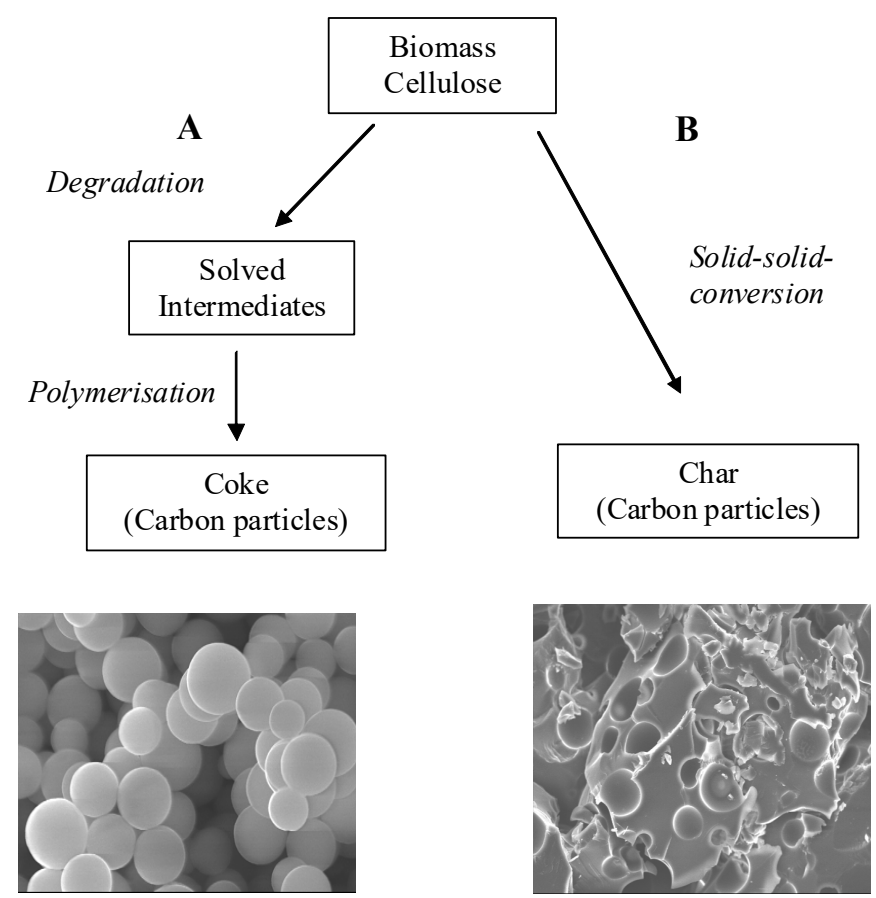

Figure 1. Primary reaction pathways A and B for the formation of HTC-coal (modified from [6]). A is a path via polymerization of solved molecules, B is a solid-to-solid conversion. The SEM pictures show hydrochar from glucose (left) and lignin (right).

Lignocellulosic biomass contains both cellulose and lignin as well as hemicellulose plus ash (Figure 2). The question is how these complex mixtures and structure behave during HTC. To study this, HTC of cellulose, lignin, straw, and beech wood was conducted. Also important is if specific differences in the structure of lignocellulosic materials, e.g., between straw and wood, have an influence on the structure of hydrochar. For comparison, some biomasses without lignin, namely cauliflower, field garlic and potato/carrot mixture as well as HMF, are converted.

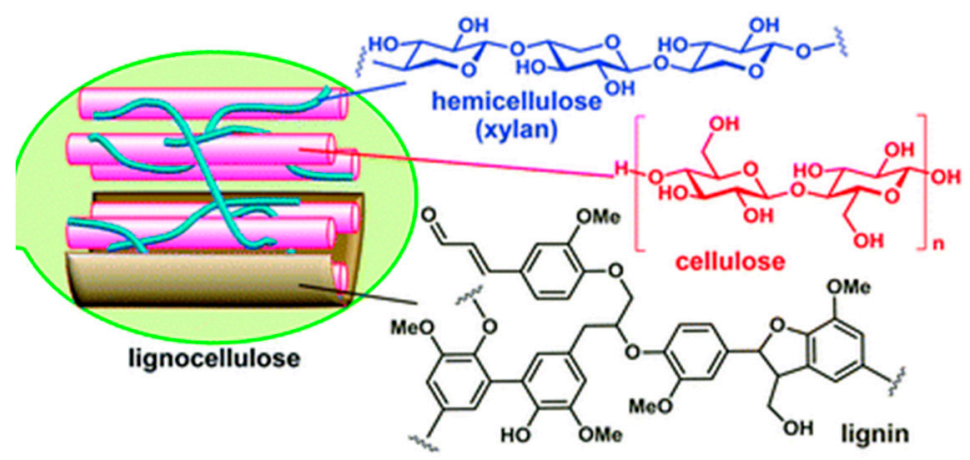

Figure 2. Structure of lignocellulose. Reproduced from Ref. [10] with permission from The Royal Society of Chemistry.

The hydrochars formed are analyzed with thermogravimetric analysis (TGA) and FTIR. TGA is a common method to study biomass [11-14] and hydrochar composition [13,15-17] and is here mainly used to detect residual cellulose from incomplete conversion of the biomass. Infrared spectra are often used to characterize hydrochar via the presence of characteristic, IR-active, functional groups (see for example: [18]). 


\section{Results and Discussion}

As usually observed $[4,5,8]$ the carbon content of the hydrochar is higher and the oxygen content is lower compared with the original biomass (Table 1). The effect is rather small for pure lignin (Table 1) [8].

Table 1. Elementary composition of the biomass and the hydrochar formed. (All data measured a relative error of around $10 \%$, for literature data see reference).

\begin{tabular}{|c|c|c|c|c|c|c|c|c|c|}
\hline Material & $\begin{array}{c}\mathrm{T} \\
{\left[{ }^{\circ} \mathrm{C}\right]}\end{array}$ & $\begin{array}{c}t \\
{[h]}\end{array}$ & $\begin{array}{c}\text { DM } \\
\text { [wt. \%] }\end{array}$ & $\begin{array}{c}\text { C } \\
\text { [wt. \%] }\end{array}$ & $\begin{array}{c}\mathbf{H} \\
\text { [wt. \%] }\end{array}$ & $\begin{array}{c}\mathbf{N} \\
\text { [wt. \%] }\end{array}$ & $\begin{array}{c}S \\
\text { [wt. \%] }\end{array}$ & $\begin{array}{c}\mathrm{O} \\
\text { [wt. \%] }\end{array}$ & $\begin{array}{c}\text { Ash } \\
\text { [wt. \%] }\end{array}$ \\
\hline & \multicolumn{9}{|c|}{ Beech Wood } \\
\hline Biomass & & & & 46 & 6.7 & 0.2 & 0.1 & 44.88 & 2.12 \\
\hline Hydrochar & 180 & 2 & 20 & 50.9 & 6.2 & 0.2 & 0 & 41.24 & 1.46 \\
\hline Hydrochar & 180 & 4 & 20 & 51.9 & 6 & 0.2 & 0 & 39.83 & 2.07 \\
\hline Hydrochar & 220 & 2 & 20 & 57.4 & 5.4 & 0.4 & 0.1 & 34.5 & 2.2 \\
\hline Hydrochar & 220 & 4 & 20 & 60.2 & 5 & 0.3 & 0.1 & 32.3 & 2.1 \\
\hline Hydrochar & 250 & 2 & 10 & 63.4 & 5.2 & 0.3 & 0.1 & 27.99 & 3.01 \\
\hline Hydrochar & 250 & 4 & 10 & 67.2 & 5.3 & 0.3 & 0.1 & 23.69 & 3.41 \\
\hline Hydrochar & 220 & 2 & 10 & 54.5 & 6 & 0.2 & 0.1 & 37.99 & 1.21 \\
\hline Hydrochar & 220 & 4 & 10 & 57.8 & 5.7 & 0.2 & 0.1 & 34.35 & 1.85 \\
\hline \multirow[t]{2}{*}{ Hydrochar } & 220 & 17 & 10 & 66.5 & 5.5 & 0.3 & 0.1 & 24.98 & 2.62 \\
\hline & \multicolumn{9}{|c|}{ Straw } \\
\hline Biomass & & & & 43.3 & 6.4 & 0.4 & 0.2 & 44.65 & 5.05 \\
\hline Hydrochar & 220 & 2 & 10 & 52.5 & 5.9 & 0.4 & 0.4 & 36.41 & 4.39 \\
\hline Hydrochar & 220 & 4 & 10 & 57 & 5.8 & 0.4 & 0.3 & 32.01 & 4.49 \\
\hline Hydrochar & 220 & 17 & 10 & 65.5 & 5.4 & 0.6 & 0.2 & 22.78 & 5.52 \\
\hline Hydrochar & 250 & 2 & 10 & 63.6 & 5.5 & 0.5 & 0.2 & 24.3 & 5.9 \\
\hline \multirow[t]{2}{*}{ Hydrochar } & 250 & 4 & 10 & 65.1 & 5.4 & 0.6 & 0.1 & 23.21 & 5.59 \\
\hline & \multicolumn{9}{|c|}{ Cauliflower } \\
\hline Biomass, [8] & & & & $45.3^{1}$ & $5.6^{1}$ & n.t. & n.t. & $46.8^{1}$ & 9.95 \\
\hline \multirow[t]{2}{*}{ Hydrochar } & 220 & 4 & 10 & 55.5 & 5.6 & 3.5 & 0.9 & n.t. & n.t. \\
\hline & \multicolumn{9}{|c|}{ Garden Garlic } \\
\hline \multirow[t]{2}{*}{ Hydrochar } & 220 & 4 & 10 & 54.7 & 5.6 & 2.8 & 0.6 & n.t. & n.t. \\
\hline & \multicolumn{9}{|c|}{ Carrots/Potatoes } \\
\hline Biomass, [19] & & & & $40.2^{1}$ & $6.3^{1}$ & $0.74^{1}$ & $0.15^{1}$ & $52.7^{1}$ & 5.7 \\
\hline \multirow[t]{2}{*}{ Hydrochar } & 220 & 4 & 10 & 63.4 & 5.5 & 1.8 & 0.3 & n.t. & n.t. \\
\hline & \multicolumn{9}{|c|}{ Lignin } \\
\hline Lignin, [8] & & & & $66^{1}$ & $6^{1}$ & n.t. & n.t. & $26.9^{1}$ & 1.33 \\
\hline \multirow[t]{2}{*}{ Hydrochar } & 220 & 4 & 10 & $75.1^{1}$ & $6.5^{1}$ & n.t. & n.t. & $18.4^{1}$ & n.t. \\
\hline & \multicolumn{9}{|c|}{ Cellulose } \\
\hline Cellulose, [8] & & & & 43.2 & 5.7 & n.t. & n.t. & 51.1 & b.d. \\
\hline Hydrochar & 220 & 4 & 10 & 68.7 & 4.3 & n.t. & n.t. & 27 & b.d. \\
\hline
\end{tabular}

Concerning the structure of biomass or hydrochar, TGA and IR analysis gives more information. Figure 3 shows the DTG curve (DTG: Differential thermogravimetry = first derivative of the TG/TGA curve) of pure cellulose, xylan as model compound for hemicelluloses and lignin. They present the main components of biomass. Xylan has the lowest thermal stability [17]. Cellulose also shows a sharp and significant peak like xylan, but at higher temperature [17]. The extent of the weight loss at a certain temperature is a direct consequence of the uniform type of chemical bonds connecting the sugar monomers to the polymeric carbohydrate. Xylan, or hemicellulose, is a branched polymer, cellulose not. As consequence, cellulose is partly crystallized, and the single polymers strains stabilized each other by hydrogen bonds. Lignin consists of different type of bonds with different thermal stability. 
As a consequence, lignin degrades in a wide range of temperatures therefore giving no clear peak in the DTG curve $[17,20]$.

The lignocellulosic materials wheat straw and beach wood consist of hemicellulose, cellulose, and lignin (Figure 2). Figure 4 shows the DTG curves of these two biomasses. Beach wood shows a characteristic cellulose peak with a shoulder, caused by hemicellulose. In the case of straw, cellulose and hemicellulose peaks coalesce to one broader one. This indicates that the structure is different, causes by differing interconnections within the material (Figure 2).

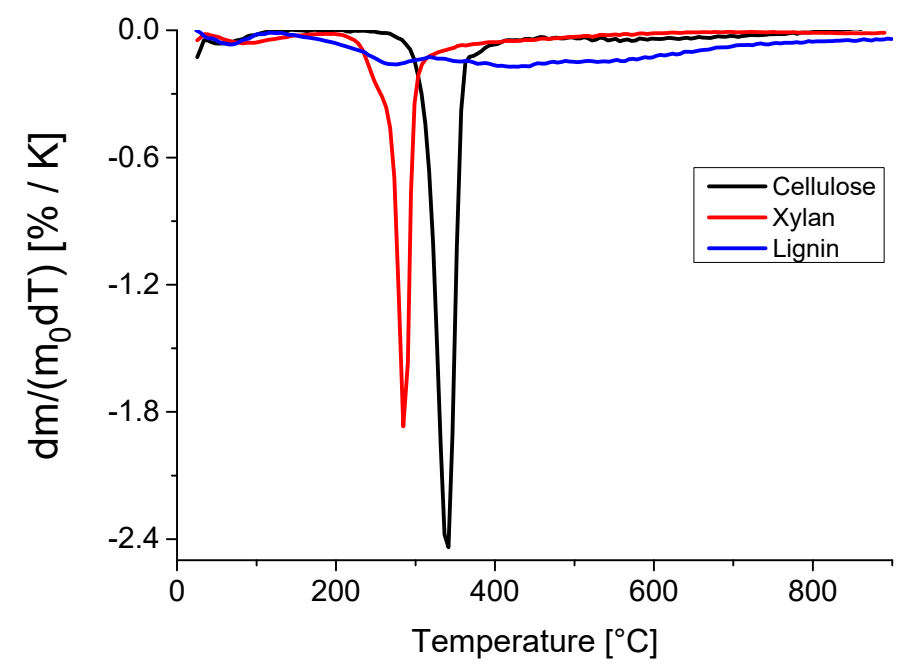

Figure 3. DTG curves of the model compounds cellulose, xylan and lignin, modified from [21].

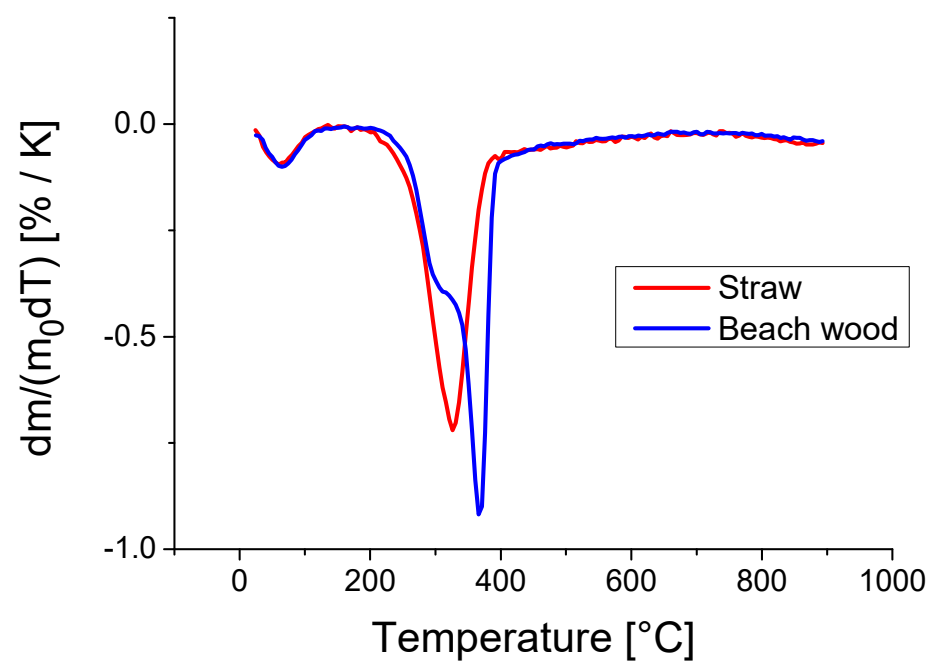

Figure 4. DTG of straw and beach wood chips, modified from [21].

Figure 5 shows the DTG curves of hydrochar produced by the HTC of beech wood at different reactions times and performed at $220^{\circ} \mathrm{C}$ carbonization temperature, bearing some resemblance with data from the literature [9]. There is no hemicellulose peak or even shoulder any more. This reminds of DTG curves recorded during "dry" torrefactions: The hemicellulose as the most reactive component is carbonized at the lowest temperature [22]. The cellulose peak is still visible but decreases with the reaction time. Compared to the biomass results (Figure 4), a small peak at around $420{ }^{\circ} \mathrm{C}$ is detected after HTC (Figure 5). This weight loss can be tentatively attributed to intermediary carbonization products, like short-chained polymers. As shown in Figure 1, hydrochar is likely to be formed via 
polymerization of solved molecules. After $17 \mathrm{~h}$ reaction (Figure 5), the residual cellulose peak and the peak or the carbonization product seems to have merged.

Figure 6 shows the DTG curve of hydrochar from straw produced at $220^{\circ} \mathrm{C}$ and different reaction times. Compared to the DTG curve of the non-carbonized biomass (Figure 4), the peak is shifted, because of the conversion of hemicellulose via carbonization. This degradation of hemicellulose as the first biomass compound is in accordance with other studies [23]. The hydrochar from straw (Figure 6) shows lower residual cellulose peaks at $2 \mathrm{~h}$ and $4 \mathrm{~h}$ reaction times, compared with the hydrochar from wood (Figure 5). In the case of straw hydrochar (Figure 6) and after $17 \mathrm{~h}$ reaction time, no "cellulose peak" is visible. Instead, the peak attributed to a carbonization product/short polymer emerged at around $420^{\circ} \mathrm{C}$. The results here are similar to studies with sugarcane bagasse [24]. The "lignin-like" behavior of hydrochars, e.g., in TGA studies, is mentioned by several authors, e.g., [25]. The results indicate that in the case of straw the shielding effect of lignin against hydrolysis is weaker than for wood.

In several studies, agricultural residues are discussed as feedstock for hydrothermal carbonization. As representatives of agricultural residues, which are not lignocellulosic like straw, different feedstock with no or very low lignin content are studied. These are cauliflower leaves, field garlic and a mixture of carrots and potatoes.

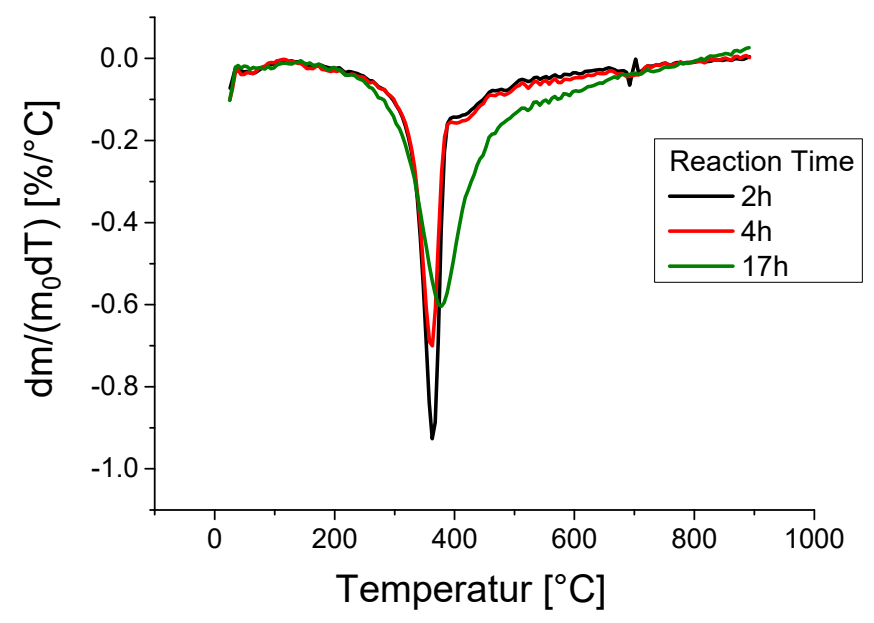

Figure 5. DTG of hydrochar from beach chips $\left(10 \%\right.$ dry mass, $\left.220^{\circ} \mathrm{C}\right)$, produced with different reaction times, modified from [21].

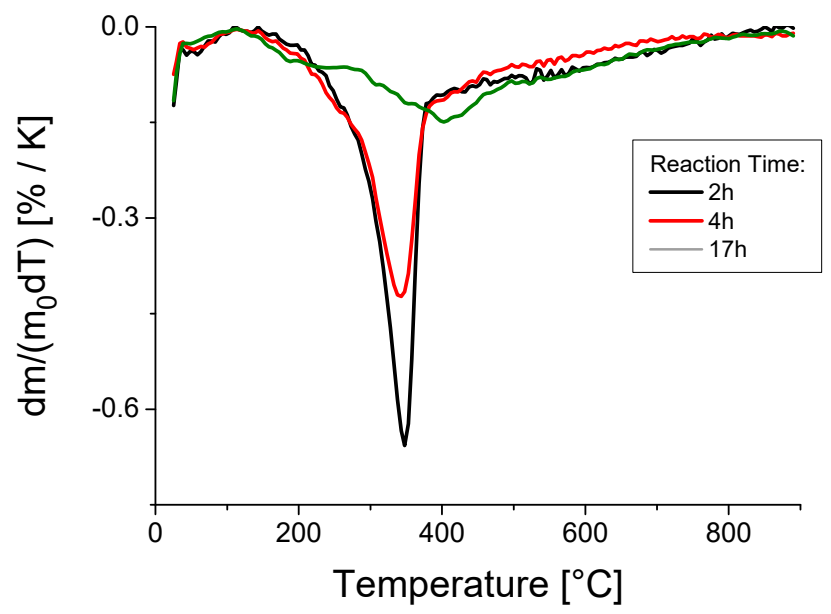

Figure 6. DTG of hydrochar from straw $\left(10 \%\right.$ dry mass, $\left.220^{\circ} \mathrm{C}\right)$, produced with different reaction times, modified from [21]. 
Figure 7 shows the DTG curves of the hydrochars from these vegetables. They are definitely completely different from the curves originating from lignocelluloses (Figures 5 and 6). For the vegetable hydrochars, the DTG curves show no cellulose peak, but the "carbonization product" peak. To support the idea that the small peak above $400{ }^{\circ} \mathrm{C}$ is a polymerization product formed during HTC, a hydrochar obtained from hydroxymethylfurfural (HMF) was analyzed. HMF being the supposed monomer involved in the polymerization to hydrochar [26]. The DTG of this hydrochar shows indeed a peak in the same range than the others; in contrast it is broader (Figure 8).

The results concerning the occurrence of a hydrochar related peak in TGA are in accordance of a study, which shows DTG curves of the products of reaction pathway A and B shown in Figure 1 [7]. In the case of lignocellulosic materials, the complex structure leads to a decrease in hydrolysis rate, especially because lignin shield cellulose from hydrolysis (Figure 2). In addition, cellulose is partly crystalline, which also reduces the hydrolysis rate. As consequence, the reaction pathway B (Figure 1) is more dominant than A. This means that although the chemistry of HTC is completely different compared with dry pyrolysis process, there some similarity with torrefaction. The ratio of reaction pathway A to B strongly depends on the structure, as the difference between straw and wood shows. The vegetables react completely via reaction pathway A (Figure 1).

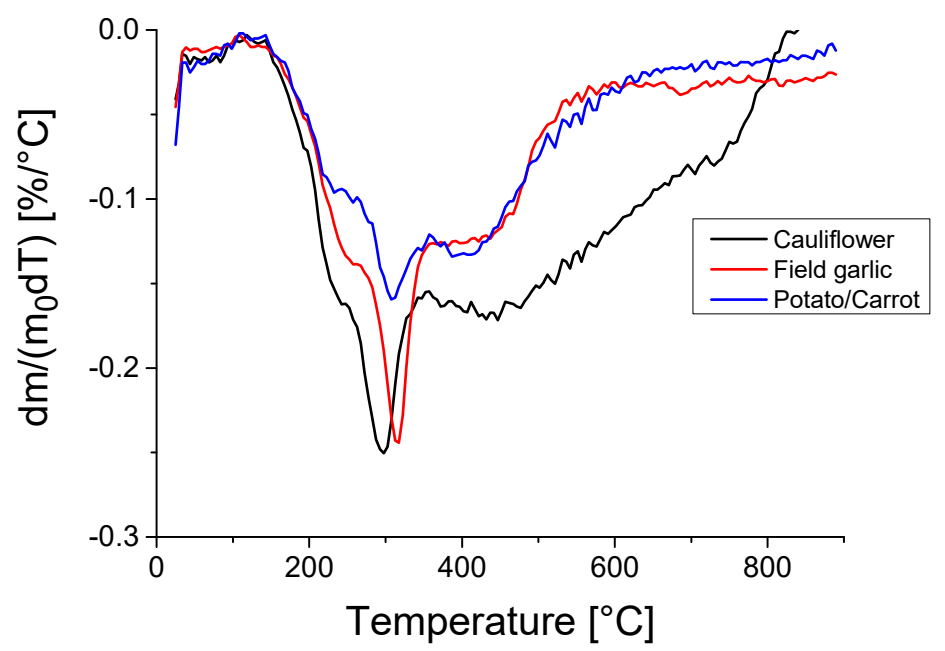

Figure 7. DTG of hydrochar cauliflower, field garlic and potato/carrot mixture $\left(22{ }^{\circ} \mathrm{C}, 10 \%\right.$ dry mass, $4 \mathrm{~h}$ ). (Modified from [21]).

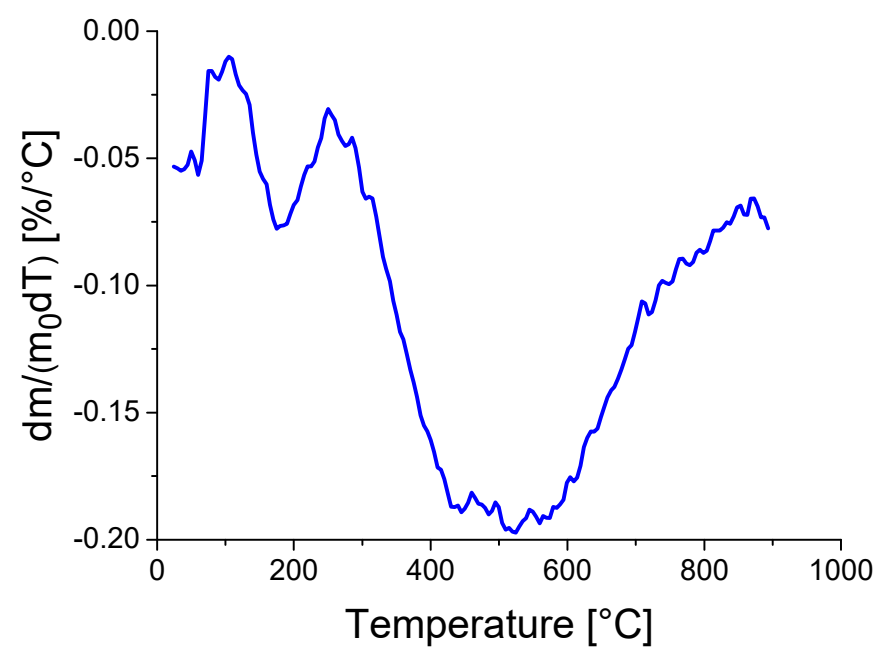

Figure 8. DTG of hydrochar from hydroxymethylfurfural. 
TGA or DTG measurements alone give no information about the general structure of hydrochars. Therefore, FTIR-measurements were conducted. Figure 9 shows the spectra of hydrochar from straw, cellulose, and lignin. The infra-red spectra give valuable info about the functional groups and structure of hydrochar. The use of this spectroscopy is common in thermochemical biomass conversion and well documented allowing a relatively easy assignment of the IR absorption bands $[27,28]$. The IR spectra of hydrochar, produced at $220^{\circ} \mathrm{C}$ (Figure 9), from straw and cellulose [17], produced are very similar: strong "stretching" adsorption bands at 3400 and $2900 \mathrm{~cm}^{-1}$ for $v(\mathrm{O}-\mathrm{H})$ and $v\left(\mathrm{C}_{\mathrm{sp}}-\mathrm{H}\right)$, a distinct $v(C=O)$-band at $1700 \mathrm{~cm}^{-1}$ and a $v(C=C)$-band at $1600 \mathrm{~cm}^{-1}$. In addition, there is a very strong adsorption band at $1100 \mathrm{~cm}^{-1}$, assigned to the stretch vibrations of the $\mathrm{C}-\mathrm{C}$ - and $\mathrm{C}-\mathrm{O}$-bonds and the deformation vibrations of the $\mathrm{CH}-, \mathrm{OH}-$ and $\mathrm{CH}_{2}$-groups of the glycosyl-units of cellulose. The spectrum of lignin hydrochar shows typical aromatic bands: pronounced $v(C=C)$-bands at around $1600 \mathrm{~cm}^{-1}$ and a deformation band $\delta(\mathrm{C}-\mathrm{H})$ (out of plane) at $830 \mathrm{~cm}^{-1}$. Strong bands at $1200 \mathrm{~cm}^{-1}$ are generally characteristic $v(\mathrm{C}-\mathrm{O})$-vibration found in ethers and phenols [17].

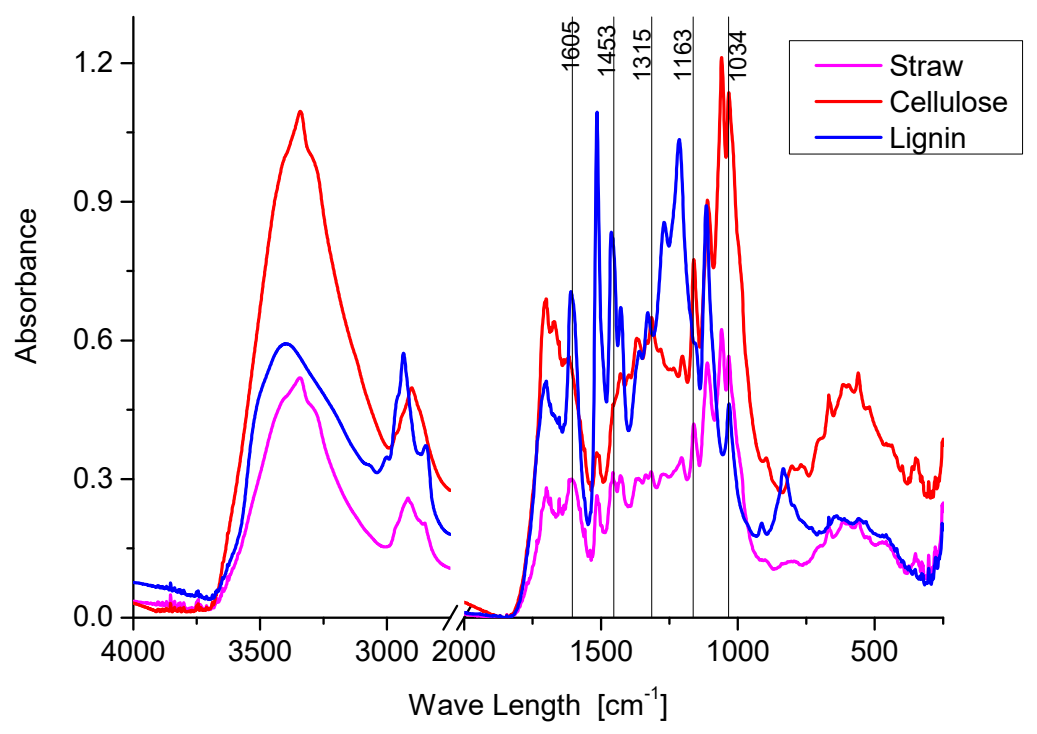

Figure 9. FTIR spectra of hydrochars from straw, cellulose, and lignin. HTC conditions: $220^{\circ} \mathrm{C}, 10 \% \mathrm{DM}$ (Dry Mater), $4 \mathrm{~h}$ reaction time (Modified from [21]).

The spectra of lignin [17] and its hydrochar, produced at $220^{\circ} \mathrm{C}$, are very similar (Figure 10). This shows the high stability of the phenolic skeleton of lignin, which is only slightly modified under HTC conditions. This is illustrated by pathway B in Figure 1; a small part of the lignin is dissolved leading to some holes in the overall structure (picture at the bottom left, in Figure 1), leaving the main structure only slightly changed. Therefore, both lignin and hydrochar shows the typical adsorption bands of intricate, cross-linked polyphenolic network. The strong adsorption bands at around 1600 and $1200 \mathrm{~cm}^{-1}$ could be mainly caused by the stretch vibrations of $\mathrm{C}=\mathrm{C}$ and $\mathrm{C}-\mathrm{O}$ bonds present in ligninic materials. Typical for aromatics is the deformation vibration $\delta(\mathrm{C}-\mathrm{H})$ (out of plane) at $830 \mathrm{~cm}^{-1}$. For the bands at 1600 and $1200 \mathrm{~cm}^{-1}$ a small contribution of the deformation vibration $(\delta)$ of $\mathrm{OH}$ - and $\mathrm{CH}$-groups of syringyl-units cannot be ruled out. Signals related to alkyl-fragments can be found at around $2800 \mathrm{~cm}^{-1}$, characteristic of $v\left(\mathrm{C}_{\mathrm{sp} 3}-\mathrm{H}\right)$ adsorption bands. In comparison, the $\mathrm{C}-\mathrm{H}$ stretching band of aromatics could not be clearly detected due to its typical low intensity $\left(v\left(\mathrm{C}_{\mathrm{sp} 2}-\mathrm{H}\right) @\right.$ $\left.3000-3100 \mathrm{~cm}^{-1}\right)$. After carbonization $\left(220^{\circ} \mathrm{C}\right)$ the $v(\mathrm{C}=\mathrm{O})$-adsorption band at $1702 \mathrm{~cm}^{-1}$ increases slightly, similar to the deformation band $\delta(\mathrm{C}-\mathrm{H})$ (out of plane) at $830 \mathrm{~cm}^{-1}$. This implies the formation of complex quinones, carboxylates and aromatics obtained via further crosslinking induced by the thermal treatment (See also [9]). 
In contrast to the results with lignin, the hydrochar from cellulose [17] gives completely different IR spectra (Figures 11 and 12, see also [9]). The spectrum of cellulose is typical for carbohydrates: stretch vibrations of $\mathrm{C}-\mathrm{C}$ and $\mathrm{C}-\mathrm{O}$ bonds and deformation vibrations of the $\mathrm{CH}-, \mathrm{OH}-$ and $\mathrm{CH}_{2}$-groups could cause strong adsorption bands between $950 \mathrm{~cm}^{-1}$ and $1200 \mathrm{~cm}^{-1}$. After carbonization, the intensity of many of these bands decreases, due the transformation of the carbohydrate structure. Concurrently, a new $v(\mathrm{C}=\mathrm{O})$ adsorption band at $1702 \mathrm{~cm}^{-1}$ occurs. This hints to the formation of quinones and carboxylate groups (e.g., ester) by the thermal treatment. The new adsorption band at $1618 \mathrm{~cm}^{-1}$ could be tentatively attributed to an overlap of $v(\mathrm{C}=\mathrm{C})$ - and $\delta(\mathrm{O}-\mathrm{H})$-vibrations (supported by the complimentary $v(\mathrm{O}-\mathrm{H})$ - band at $\left.3416 \mathrm{~cm}^{-1}\right)$. The complex and broad overlapping of adsorption bands between 1200 and $1450 \mathrm{~cm}^{-1}$ as well as the decrease of the $v(\mathrm{C}-\mathrm{O})$ - and $v(\mathrm{O}-\mathrm{H})$-bands at 3400 plus the $v(\mathrm{C}-\mathrm{H})$-band at $2900 \mathrm{~cm}^{-1}$ suggests a dehydration and partial aromatization of the material during thermal treatment. The results reported here are in accordance with other studies, e.g., $[9,23]$. Kang et al. for instance showed that the carbonization is connected to a decrease of crystallinity, as measured by X-ray diffraction (XRD) [9]. It is obvious that after the loss of OH-groups, no hydrogen bonds, main driver for the crystallinity of the material, can be formed. This is also in agreement with the concept of the formation of hydroxymethylfurfural (HMF) as intermediate polymerizing to hydrochar. The formation of HMF is a water elimination with the loss of $\mathrm{OH}$-groups with formation of an aromatic structure [1].

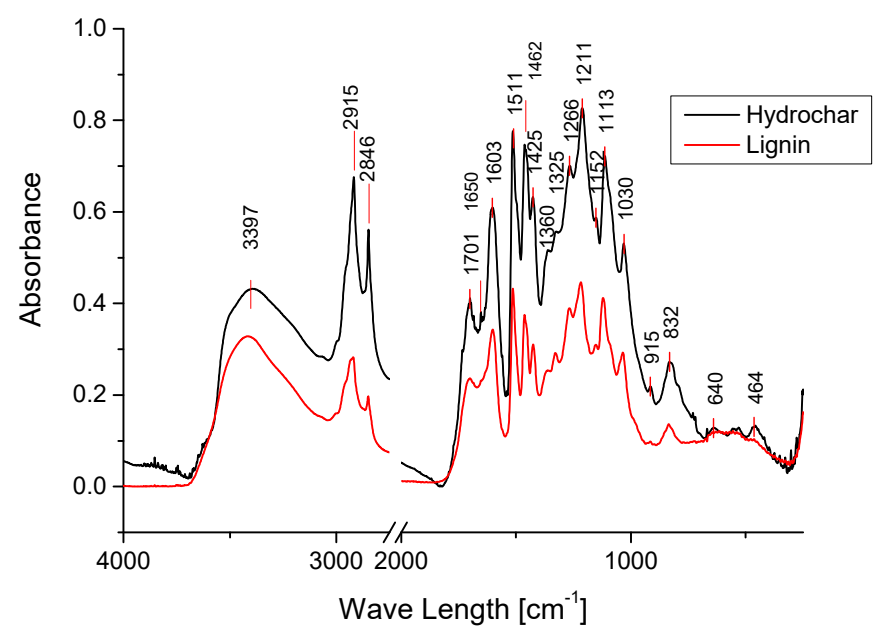

Figure 10. IR spectra of lignin and its hydrochar (10\% DM, $\left.220^{\circ} \mathrm{C}, 4 \mathrm{~h}\right)$. (Modified from [21]).

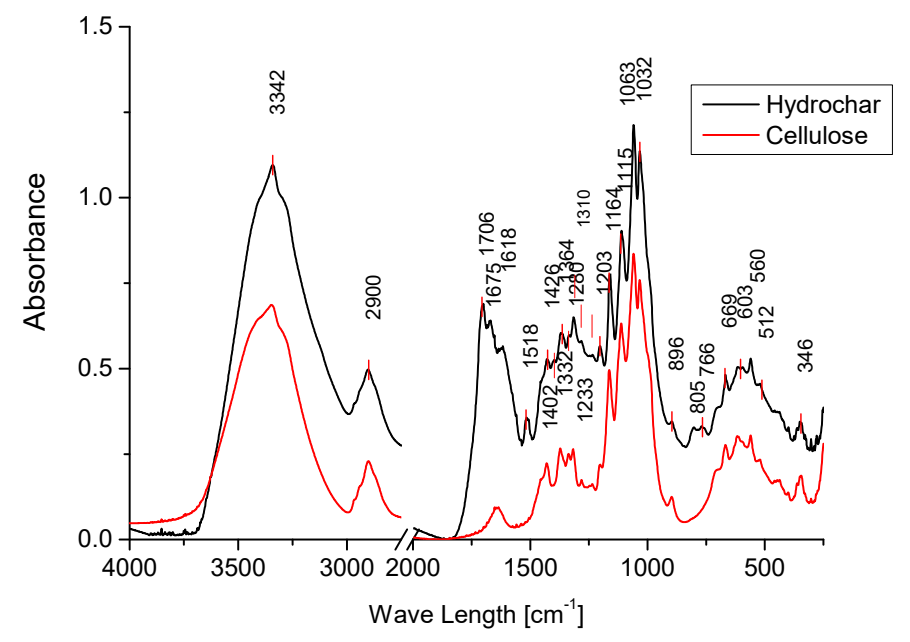

Figure 11. IR spectra of cellulose and its hydrochar $\left(10 \% \mathrm{DM}, 220^{\circ} \mathrm{C}\right.$, and $\left.2 \mathrm{~h}\right)$. (Modified from [21]). 
Comparing the hydrochar IR spectrum from cellulose produced at $220^{\circ} \mathrm{C}$ (Figure 11) with that of the hydrochar produced at $250^{\circ} \mathrm{C}$ (Figure 12), the decrease of the typical carbohydrate vibration bands is obvious. This is in line with the DTG measurement of the lignocellulosic biomasses (Figures 5 and 6): with increasing HTC-temperatures, a larger amount of cellulose is carbonized (see also [4]).

The hydrochars from straw and beech wood, produced at $220^{\circ} \mathrm{C}, 4 \mathrm{~h}$ reaction time and $10 \%$ dry mass, are post-treated in a nitrogen flow at $490{ }^{\circ} \mathrm{C}$ and $700{ }^{\circ} \mathrm{C}$, respectively. The DTG curves of the post-treated hydrochars are shown in Figure 13. They are very similar for the different post-treatment temperatures. The cellulose peak is gone, in agreement with other studies showing that thermal treatment of different hydrochars or biomass actually levels the final characteristics of the hydrochars [29].

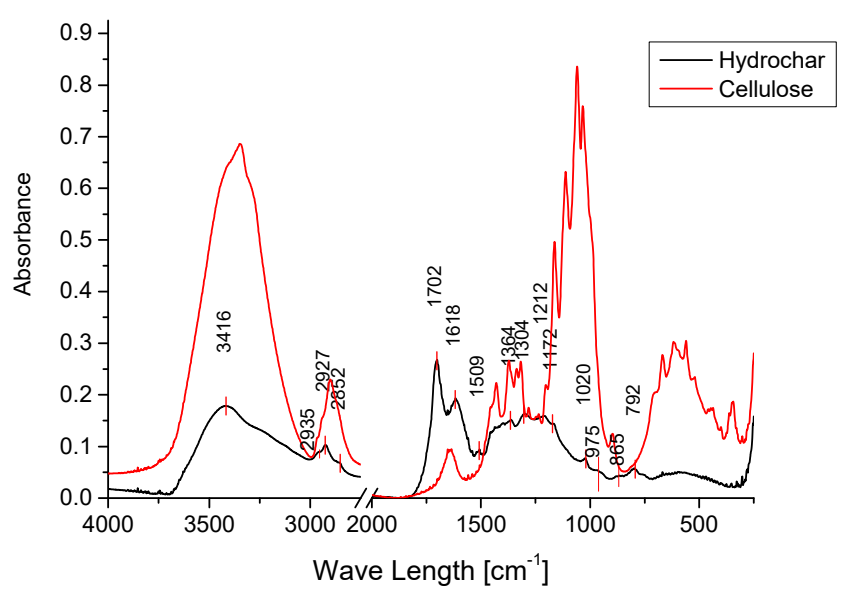

Figure 12. IR spectra of cellulose and its hydrochar $\left(20 \% \mathrm{DM}, 250{ }^{\circ} \mathrm{C}\right.$, and $\left.2 \mathrm{~h}\right)$. (Modified from [21]).

The DTG comparison of beech wood and straw post-treated hydrochars shows a peak at $700{ }^{\circ} \mathrm{C}$ for beech wood (Figure 13). This is typical for beech wood lignin [22]. In general, the DTG curves of the post-treated hydrochars are similar to that recorded for lignin (Figure 3).

In addition, the IR-spectra of the post-treated hydrochars are very similar (Figure 14). Broad adsorption bands at 1600 and $1200 \mathrm{~cm}^{-1}$ and the decrease of the $v(\mathrm{C}-\mathrm{O})$-band at $1700 \mathrm{~cm}^{-1}$, the $v(\mathrm{O}-\mathrm{H})$-band at $3400 \mathrm{~cm}^{-1}$ plus the $v\left(\mathrm{Csp}_{3}-\mathrm{H}\right)$-band at $2900 \mathrm{~cm}^{-1}$ show that further dehydration and aromatization take place during thermal post-treatment. In comparison to the spectrum of lignin hydrochar, produced at $220^{\circ} \mathrm{C}$ (Figure 14), the bands characteristic for alkyl-chains, alcohols (e.g., phenols) and quinones decreases by post-treatment.

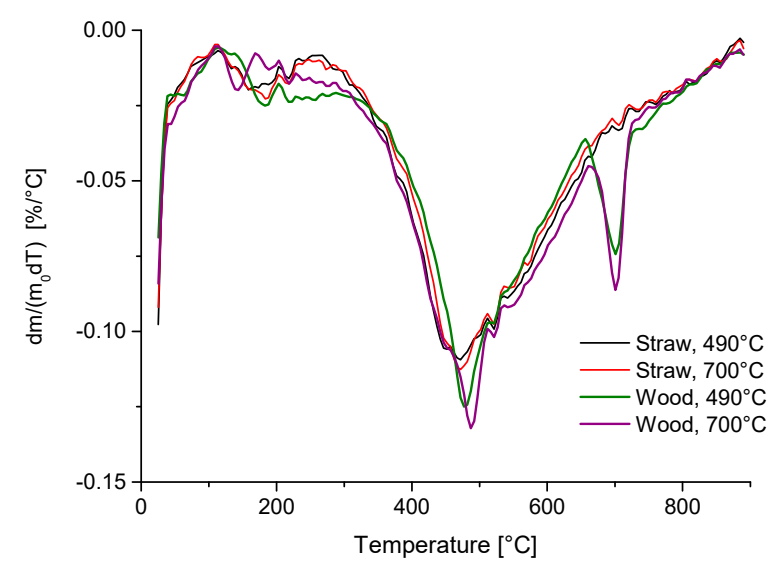

Figure 13. DTG of thermal treated hydrochars of beech wood and straw at 490 and $700{ }^{\circ} \mathrm{C}$, respectively. (Modified from [21]). 
The results reported above give some hints about what kind of chemical conversion occurs. Hydrothermal carbonization of carbohydrates can be regarded as a hydrolysis to sugars followed by water elimination to produce furfurals with a consecutive poly-condensation (Figure 1). In the case of lignocelloses, the lignin network shields the cellulose from hydrolysis (Figure 2). Therefore, cellulose peaks are visible in DTG after HTC at lower temperatures and/or shorter reaction times. This was illustrated by the cellulose peak in DTG and stronger OH-stretching/deformation bands in IR measurements. The results are in accordance with HTC studies performed with coconut fiber and dried eucalyptus leaves [30].

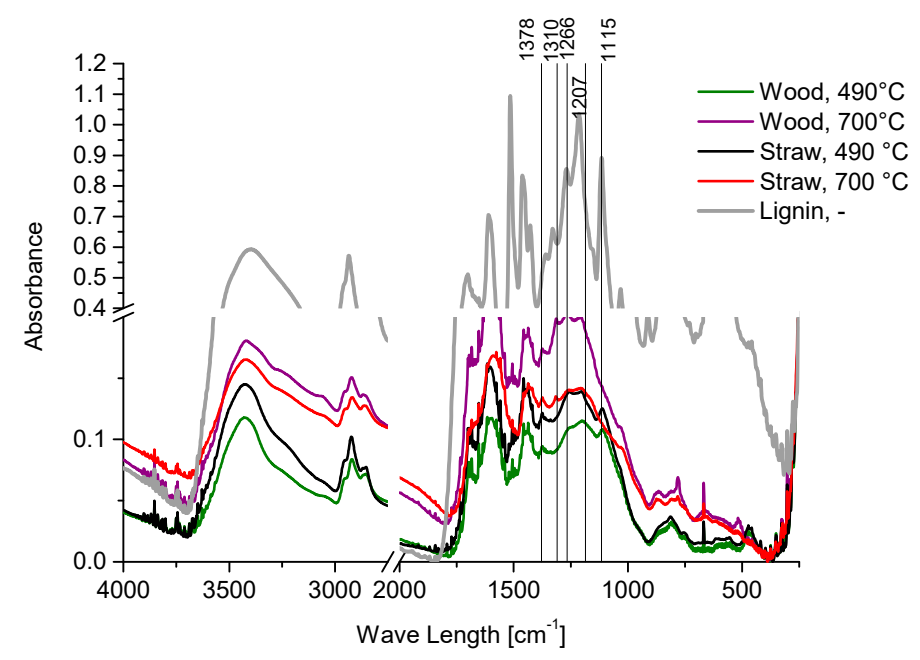

Figure 14. FTIR spectra of thermal post-treated hydrochar from beech wood and straw. Post-treatment temperatures were 490 and $700{ }^{\circ} \mathrm{C}$. For comparison, the spectrum of a not post-treated hydrochar from lignin is added (HTC: $\left.220^{\circ} \mathrm{C}, 4 \mathrm{~h}, 10 \% \mathrm{DM}\right)$. (Modified from [21]).

\section{Materials and Methods}

The experiments were conducted in autoclaves with an internal volume of $10 \mathrm{~mL}$ (for details see [8]). The biomass feedstocks studied were model compounds like cellulose, xylan and lignin. In addition, straw, beech wood, cauliflower leaves, field garlic and a mixture of carrots with potatoes was used. The composition of the lignocellulosic feedstocks is given in Table 2.

Table 2. Composition of the lignocelluloses (data from [31]).

\begin{tabular}{ccccc}
\hline Biomass & $\begin{array}{c}\text { Cellulose } \\
\text { [wt. \%] }\end{array}$ & $\begin{array}{c}\text { Hemicellulose } \\
\text { [wt. \%] }\end{array}$ & $\begin{array}{c}\text { Lignin } \\
\text { [wt. \%] }\end{array}$ & $\begin{array}{c}\text { Others } \\
\text { [wt. \%] }\end{array}$ \\
\hline $\begin{array}{c}\text { Wheat } \\
\text { Stroh } \\
\text { Beech }\end{array}$ & 38 & 29 & 15 & 18 \\
Wood & 45 & 22 & 22 & 11 \\
\hline
\end{tabular}

The feedstock was milled, in the case of biomass, and carefully mixed before use. Furnaces were used for heating. Pressure in the autoclaves was triggered via the filling level. The autoclaves were filled with crushed biomass and water. The dry matter (DM) content was 10 or $20 \mathrm{wt} \%$. After cooling, the autoclave was opened in a gas-tight container, such that the gas volume and gas composition could be determined. The product mixture was filtered and dried at $80^{\circ} \mathrm{C}$ over night. The element composition of the hydrochars was determined (using Elementar Vario EL III, Elementar Analysensysteme GmbH, Elementar-Straße 1, 63505 Langenselbold, Germany). A thermogravimetric balance TGA851 by Mettler-Toledo (STARe-Software version 16.00, by Mettler-Toledo, Ockerweg 3, 
35396 Gießen, Germany) measured the thermal behavior. Here, $8 \mathrm{mg}$ are heated with $10 \mathrm{~K} / \mathrm{min}$ up to $900{ }^{\circ} \mathrm{C}$ in nitrogen atmosphere. In addition, the solid product is characterized as $\mathrm{KBr}$-pellets using a Varian IRFT spectrometer (Varian 660).

The post-heating experiments were also done in identical autoclaves. Here the HTC coal and nitrogen was filled in the autoclave and heated to temperature up to 490 or $700{ }^{\circ} \mathrm{C}$. The solid is analyzed in the same way as described above.

Acknowledgments: The authors thank the KIC InnoEnergy Project XgaTe for financial support. The measurements of the DTG by Marion Lenzer, the preparation of the hydrochars and the post-treated hydrochars by M. Kirchherr and S. Gaag is gratefully acknowledged. Special thanks to Mathias Pagel for the construction of the autoclaves used in this study.

Author Contributions: Andrea Kruse has written the article using data from a German report [21] and made the interpretation of DTG curves. Thomas A. Zevaco performed and discussed the FTIR-results.

Conflicts of Interest: The authors declare no conflict of interest.

\section{References}

1. Titirici, M.-M.; Antonietti, M.; Baccile, N. Hydrothermal carbon from biomass: A comparison of the local structure from poly- to monosaccharides and pentoses/hexoses. Green Chem. 2008, 10, 1204. [CrossRef]

2. Titirici, M.-M. Hydrothermal Processes Sustainable Carbon Materials from Hydrothermal Processes; John Wiley \& Sons, Ltd.: Hoboken, NJ, USA, 2013.

3. Kruse, A.; Dahmen, N. Hydrothermal biomass conversion: Quo vadis? J. Supercrit. Fluids 2017. [CrossRef]

4. Libra, J.A.; Ro, K.S.; Kammann, C.; Funke, A.; Berge, N.D.; Neubauer, Y.; Titirici, M.-M.; Fühner, C.; Bens, O.; Kern, J.; et al. Hydrothermal carbonization of biomass residuals: A comparative review of the chemistry, processes and applications of wet and dry pyrolysis. Biofuels 2011, 2, 71-106. [CrossRef]

5. Funke, A.; Ziegler, F. Hydrothermal carbonization of biomass: A summary and discussion of chemical mechanisms for process engineering. Biofuels Bioprod. Biorefin. 2010, 4, 160-177. [CrossRef]

6. Karayıldırım, T.; Sınağ, A.; Kruse, A. Char and Coke Formation as Unwanted Side Reaction of the Hydrothermal Biomass Gasification. Chem. Eng. Technol. 2008, 31, 1561-1568. [CrossRef]

7. Funke, A.; Reebs, F.; Kruse, A. Experimental comparison of hydrothermal and vapothermal carbonization. Fuel Process. Technol. 2013, 115, 261-269. [CrossRef]

8. Dinjus, E.; Kruse, A.; Tröger, N. Hydrothermal Carbonization-1. Influence of Lignin in Lignocelluloses. Chem. Eng. Technol. 2011, 34, 2037-2043. [CrossRef]

9. Kang, S.; Li, X.; Fan, J.; Chang, J. Characterization of Hydrochars Produced by Hydrothermal Carbonization of Lignin, Cellulose, d-Xylose, and Wood Meal. Ind. Eng. Chem. Res. 2012, 51, 9023-9031. [CrossRef]

10. Kobayashi, H.; Fukuoka, A. Synthesis and utilisation of sugar compounds derived from lignocellulosic biomass. Green Chem. 2013, 15, 1740. [CrossRef]

11. Leroy, V.; Cancellieri, D.; Leoni, E. Thermal degradation of ligno-cellulosic fuels: DSC and TGA studies. Thermochim. Acta 2006. [CrossRef]

12. Zhou, H.; Long, Y.; Meng, A.; Li, Q.; Zhang, Y. The pyrolysis simulation of five biomass species by hemicellulose, cellulose and lignin based on thermogravimetric curves. Thermochim. Acta 2013, 566, 36-43. [CrossRef]

13. Islam, M.A.; Asif, M.; Hameed, B.H. Pyrolysis kinetics of raw and hydrothermally carbonized Karanj (Pongamia pinnata) fruit hulls via thermogravimetric analysis. Bioresour. Technol. 2014, 179, 227-233. [CrossRef]

14. Jakab, E.; Faix, O.; Till, F. Thermal decomposition of milled wood lignins studied by thermogravimetry/mass spectrometry. J. Anal. Appl. Pyrolysis 1997, 40-41, 171-186. [CrossRef]

15. Liu, Z.; Quek, A.; Kent Hoekman, S.; Srinivasan, M.P.; Balasubramanian, R. Thermogravimetric investigation of hydrochar-lignite co-combustion. Bioresour. Technol. 2012. [CrossRef] [PubMed]

16. Yang, W.; Shimanouchi, T.; Kimura, Y. Characterization of the Residue and Liquid Products Produced from Husks of Nuts from Carya cathayensis Sarg by Hydrothermal Carbonization. ACS Sustain. Chem. Eng. 2015, 3, 591-598. [CrossRef] 
17. Yang, H.; Yan, R.; Chen, H.; Lee, D.H.; Zheng, C. Characteristics of hemicellulose, cellulose and lignin pyrolysis. Fuel 2007, 86, 1781-1788. [CrossRef]

18. Reza, M.T.; Uddin, M.H.; Lynam, J.G.; Hoekman, S.K.; Coronella, C.J. Hydrothermal carbonization of loblolly pine: Reaction chemistry and water balance. Biomass Convers. Biorefin. 2014, 4, 311-321. [CrossRef]

19. Kruse, A.; Gawlik, A. Biomass Conversion in Water at $330-410{ }^{\circ} \mathrm{C}$ and $30-50 \mathrm{MPa}$. Identification of Key Compounds for Indicating Different Chemical Reaction Pathways. Ind. Eng. Chem. Res. 2003, 42, $267-279$. [CrossRef]

20. Carrier, M.; Loppinet-Serani, A.; Denux, D.; Lasnier, J.-M.; Ham-Pichavant, F.; Cansell, F.; Aymonier, C. Thermogravimetric analysis as a new method to determine the lignocellulosic composition of biomass. Biomass Bioenergy 2011, 35, 298-307. [CrossRef]

21. Kruse, A.; Kirchherr, M.; Gaag, S.; Zevaco, T.A. Hydrothermale Karbonisierung. 4. Thermische Eigenschaften der Produkte. Chem. Ing. Tech. 2015, 87, 1707-1712. [CrossRef]

22. Chen, W.-H.; Kuo, P.-C. A study on torrefaction of various biomass materials and its impact on lignocellulosic structure simulated by a thermogravimetry. Energy 2010, 35, 2580-2586. [CrossRef]

23. Reza, M.T.; Wirth, B.; Lüder, U.; Werner, M. Behavior of selected hydrolyzed and dehydrated products during hydrothermal carbonization of biomass. Bioresour. Technol. 2014, 169, 352-361. [CrossRef] [PubMed]

24. Chen, W.-H.; Ye, S.-C.; Sheen, H.-K. Hydrothermal carbonization of sugarcane bagasse via wet torrefaction in association with microwave heating. Bioresour. Technol. 2012, 118, 195-203. [CrossRef] [PubMed]

25. Xiao, L.-P.; Shi, Z.-J.; Xu, F.; Sun, R.-C. Hydrothermal carbonization of lignocellulosic biomass. Bioresour. Technol. 2012, 118, 619-623. [CrossRef] [PubMed]

26. Kruse, A.; Funke, A.; Titirici, M.-M. Hydrothermal conversion of biomass to fuels and energetic materials. Curr. Opin. Chem. Biol. 2013, 17, 515-521. [CrossRef] [PubMed]

27. Xu, F.; Yu, J.; Tesso, T.; Dowell, F.; Wang, D. Qualitative and quantitative analysis of lignocellulosic biomass using infrared techniques: A mini-review. Appl. Energy 2013, 104, 801-809. [CrossRef]

28. Kabyemela, B.M.; Adschiri, T.; Malaluan, R.M.; Arai, K. Glucose and Fructose Decomposition in Subcritical and Supercritical Water: Detailed Reaction Pathway, Mechanisms, and Kinetics. Ind. Eng. Chem. Res. 1999, 38, 2888-2895. [CrossRef]

29. Rodriguez Correa, C.; Bernardo, M.; Ribeiro, R.P.P.L.; Esteves, I.A.A.C.; Kruse, A. Evaluation of hydrothermal carbonization as a preliminary step for the production of functional materials from biogas digestate. J. Anal. Appl. Pyrolysis 2017, 124, 461-474. [CrossRef]

30. Liu, Z.; Quek, A.; Kent Hoekman, S.; Balasubramanian, R. Production of solid biochar fuel from waste biomass by hydrothermal carbonization. Fuel 2013, 103, 943-949. [CrossRef]

31. Kaltschmitt, M.; Hartmann, H.; Hofbauer, H. Energie aus Biomasse; Springe: Berlin/Heidelberg, Germany, 2009.

(C) 2018 by the authors. Licensee MDPI, Basel, Switzerland. This article is an open access article distributed under the terms and conditions of the Creative Commons Attribution (CC BY) license (http:/ / creativecommons.org/licenses/by/4.0/). 